\title{
Social Attributes And Economic Instability In Africa
}

Amon O. Okpala, (Email: aokpala@uncfsu.edu), Fayetteville State University Petur O. Jonsson, (Email: pjonsson@uncfsu.edu), Fayetteville State University

\begin{abstract}
How do the social characteristics of African economies affect their relative economic stability? This paper offers a new nominal definition of economic instability in terms of average standard deviations from the exponential growth path suggested by neoclassical growth theory under ideal conditions. We used the portion of the population that subsists on agriculture as an indication of how diverse and adaptable any particular economy is. Literacy rates may serve as a proxy for the quality and adaptability of the labor force in the various countries. Other variables used are urban population as a percentage of total population, life expectancy, infant mortality rates and the corruption perception index. These variables were all statistically significant in explaining economic instability with the expectation of corruption perception index and infant mortality rates which were statistically insignificant.
\end{abstract}

\section{Introduction}

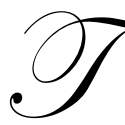

he lack of sustainable economic growth and development in Africa are partly due to the political, social and economic instability. Lawlessness, evidenced by a lack in the protection of private property rights from violence, corruption and other acts of predation are quite pervasive in most African countries. ${ }^{1}$ Investors need an environment that allows them to allocate resources efficiently, and where property rights are legally protected. Unless investors are confident that policies will remain reasonably stable over time, they will not invest in such an economy. ${ }^{2}$

It is increasingly obvious that the credibility of government in promoting the rules of law, especially that of protecting private property, and reducing social and economic injustices, are critical foundations for market-led growth and development. This paper focuses on how the social attributes of developing countries affect their relative economic stability. Limited availability of data, along with measurement and specification problems, have long made answers hard to come by.

In this context, this paper builds on the approach to the measurement and specification of economic instability in the absence of reliable inflation data that was developed by Jonsson and Okpala (1997). Specifically, the paper focuses on nominal stability, measured in terms of how well countries follow the exponential nominal growth paths that neoclassical growth theory suggests, based on stable inflation and steady real growth rates. Once a measure of economic instability, defined in terms of average standardized deviations from this growth path, has been obtained, the paper conducts a cross-sectional analysis of how some of the social attributes of countries on the African continent affect their relative economic stability.

\section{On The Sources Of Economic Instability}

It should be noted that the economies of Africa are quite heterogeneous. Their history, population density, income distribution, openness, industrialization, and infrastructure etc. differ greatly. As a result, this

Readers with comments or questions are encouraged to contact the authors via email.

paper will not pretend to identify all the various factors that have affected the economic stability of these diverse economies. In what follows, we will therefore focus on easily measured characteristics like GDP per capita, literacy 
rates, infant mortality rates etc. Still, it is helpful to consider some of the global trends that shaped economic stability and economic growth from 1964 to 1993.

One important trend has been the growth of international trade, or the globalization of economic activity. Thus world exports "grew at a compound annual rate of 12.7 percent a year in dollar terms" (Little et al., 1993, p. 12) over the quarter century from 1965 to 1990 . While most of this growth in world exports was based on manufactured goods, many African economies (especially in Sub-Saharan Africa) rely mostly on the exports of primary products like oil, minerals, and agricultural commodities to finance their international trade. As a result, the world export share of these economies has declined. Moreover, these economies are particularly vulnerable to the effects of fluctuations in the price of their exports. Thus fluctuations in oil prices have had a significant impact on the Nigerian economy; while fluctuating coffee prices have affected Cameroon and Kenya.

At the same time, the international monetary order and the international flow and availability of credit have gone through a number of changes that have had a significant impact on the growth and stability of the African economies (see Little et al., 1993, Chapters 3-5). In particular, tightening of credit for LDCs has contributed to slower growth of these economies in the last decade we consider.

It is very difficult to come up with a single measure of either how vulnerable an economy is to fluctuations in the prices of primary commodities, or how well prepared it is to handle global changes in credit conditions etc. Still, we believe that the portion of the population of a country that subsists on agriculture should give us some indication of how diverse and adaptable that particular economy is. That is, the smaller the percentage of the population engaged in agriculture, the greater the versatility and robustness of economy. Of course, this measure is far from perfect. But given the limited data available from many of the developing countries, it is the one consistent proxy for economic diversity and adaptability that we can find for virtually all the economies in question. As for the quality and adaptability of the labor force in the various countries, we believe that life expectancy rates may serve as a proxy.

An additional complication is the fact that most low to middle income countries have dual economies. On the one hand, these economies have a large traditional subsistence agricultural sector, with peasants who produce primarily for their own families and villages. On the other hand, in the midst of these labor-intensive subsistence farm economies, we do find urban enclaves with modern manufacturing and processing operations. These enclaves in turn attract idle and unproductive labor from the rural sectors. This contributes to the congestion and overpopulation of the major cities. The point is, the urban areas of LDCs are not only experiencing a rapid increase in population, but are also serving as a magnet for underemployed and poorly paid rural workers. Moreover, the urban growth of Africa has increased the premium on urban space and has thus made it hard, if not impossible, for the urban poor to afford adequate housing. This lack of adequate physical facilities degrades quality of life in most of the inner cities and hampers economic development in a variety of ways. Indeed, because of these problems it is possible that urbanization may to some extent contribute to economic instability in Africa.

Furthermore, the pervasiveness of corruption, or the perception of corruption by entrepreneurs, and the general public can be a great source of economic instability in Africa. Civil servants, politicians, and judges have access to valuable benefits, and can use their position for private gains by accepting illegal payments. According to the survey of entrepeneurs, and other private individuals concerning obstacles associated with uncertain property rights and dealing with arbitrariness - crime ${ }^{3}$ and corruption ranked among the top three in Africa (see, World Development Report, 1997). Corruption is quite prevalent in Africa for many reasons. Firstly, the probability of being caught and punished is extremely low. Secondly, the incentives for corrupt behavior exists because opportunities are generated by the policy environment, coupled with the wide discretion and lack of accountability that government workers have. Overall, corruption will increase in any society when the expected benefit for corrupt behavior outweighs the expected cost. The consequences of corruption may not end with paying off officials, but may include other arbitrary government time-consuming and economically unproductive relations (see, World Development Report, 1997). An efficient use of government official power can contribute powerfully to sustainable development, but its misuse can create serious problems of credibility, erode the constituency for development programs and humanitarian relief, and could further economic instability. 


\section{A Measure Of Economic Instability}

As explained by Heston (1994) and Ahmad (1994), it is difficult if not impossible to find reliable inflation data for many developing economies, including most of the developing economies of Africa. For these economies we cannot in practice separate real from nominal fluctuations, and thus have no choice but to use nominal data.

Fortunately, since that is what we must work with, we have some theoretical justifications for the use of nominal data in this paper. To see this, let us consider the definition of economic stability and stabilization. Much of the literature on economic stabilization focuses on the stabilization of nominal aggregate income. Presumably, a single nominal income target captures aspects of both real income and price-level stabilization. Moreover, a number of recent theoretical papers (see for example Hall and Mankiw (1994) and Frankel and Chinn (1995)) make the case that nominal income stabilization yields greater stability of both income and prices than stabilization of any other single target.

However, the empirical literature has been a little confused about how to specify nominal income targets and how to measure fluctuations from the optimal trend of nominal GDP. In particular, the literature has so far mostly used either absolute or squared deviations from a supposedly linear trend of GDP (or GNP) to indicate economic instability. It is easily demonstrated that this is not appropriate.

A given real GDP growth rate, $r_{t}$, along with some specified inflation rate, $\pi_{t}$, would yield a nominal economic growth rate of $g_{t}=r_{t}+\pi_{t}+r_{t} \pi_{t}$ in any given period $t$. This means that constant real growth along with stable inflation would give rise to a fixed nominal growth rate, $g$, for the economy. Given such a fixed growth rate, $g$, an economy's nominal GDP in any given period $t>0$, would be $Y_{t}=Y_{0} \prod_{j=1}^{t}(1+g)^{j}$. In other words, in a stable economy, or an economy with a fixed nominal growth rate, nominal GDP follows an exponential rather than a linear path over time.

So, we must look at deviations from the appropriate exponential trend if we want an indicator of how unstable an economy is. That is, we need to consider how actual GDP, or $Y_{t}$, differs from the imputed value of GDP, or $\hat{Y}_{t}=Y_{0} \prod_{j=1}^{t}(1+\hat{g})^{j}$, where $\hat{g}$ represents the best fitting constant nominal growth rate (also called NGROWTH in the empirical part below). Once we know $\hat{g}$ (or NGROWTH), we can find $\hat{Y}_{t}$, and this in turn allows us to find the average percent deviation of actual GDP from the fitted exponential trend generated by $\hat{g}$, as

$$
\bar{\varepsilon}=\frac{\sum_{t=1}^{T}\left|\left(Y_{t}-\hat{Y}_{t}\right) / Y_{t}\right|}{T} \times 100 .
$$

As explained in an earlier paper (Jonsson and Okpala, 1997), $\bar{\varepsilon}$ can be interpreted as a measure of economic instability.

\section{Data And Results}

Nominal GDP data for the various economies of Africa was obtained from the IMF International Financial Statistics database. We used data from 1964 to 1993 to estimate $\hat{g}$ (or NGROWTH) by fitting the data to trend, using the exponential trend procedures of Minitab 10.2. This in turn gave us estimates of $\bar{\varepsilon}$ (referred to as INSTAB) contained in Table 1 below. A casual examination of Table 1 will show that Uganda had the highest estimate of 122, while Mauritania has the lowest estimate of 5.02.

Table 1: Economic Instability Estimate for Various African Nations. 


\begin{tabular}{|c|c|c|c|c|c|}
\hline Country & INSTAB & Country & INSTAB & Country & INSTAB \\
\hline Algeria & 15.17 & Kenya & 6.19 & Senegal & 8.78 \\
\hline Benin & 13.71 & Lesotho & 13.39 & Sierra Leone & 85.08 \\
\hline Cameroon & 20.50 & Madagascar & 19.28 & South Africa & 6.88 \\
\hline Central African & 14.03 & Malawi & 11.35 & Tanzania & 27.09 \\
\hline Congo & 21.25 & Mali & 12.25 & Togo & 6.29 \\
\hline Egypt & 17.45 & Mauritania & 5.02 & Tunisia & 8.05 \\
\hline Ethiopia & 24.10 & Morocco & 6.40 & Uganda & 122.06 \\
\hline Gabon & 41.30 & Niger & 18.29 & Zambia & 80.46 \\
\hline Gambia & 15.96 & Nigeria & 25.14 & Zimbabwe & 9.31 \\
\hline Ghana & 47.86 & Rwanda & 10.99 & & \\
\hline
\end{tabular}

Next, we obtained literacy rates (LITERACY), and the portion of the labor force working in agriculture (AGRICULT), from the CIA World Factbook (Central Intelligence Agency, 1993). We obtained infant mortality rates per 1000 live births (INFMORT), life expectancy (LEXPECT) and urban population as a percentage of total population (URBAN) from the World Development Report (1998).

Data on the perception of the degree of corruption by businessmen, risk analysts and the general public (PCI) was obtained from the Corruption Perception Index 1998 Data. ${ }^{4}$ PCI ranges from 10 (highly clean nation), to 0 (highly corrupt nation). Table 2 shows the responses from 3,600 entrepreneurs on their view on sixty-nine nations about corruption, crime and other institutional frameworks, (World Development Report, 1997). The table shows the result of the rankings of obstacles to doing business. It is remarkable that corruption ranked as the worst obstacle in Africa. According to a report by The World Bank Group (1996), corruption hinders economic efficiency, diverts resources from the poor to the rich, increases the cost of business, distorts public expenditures, and deters foreign investors.

Table 2: Firms' Rankings of Obstacles to Doing Business. (Worst $=1$ ).

\section{OBSTACLES: $\quad$ Sub-Saharan Africa. $\quad$ Latin America \& Caribbean. $\quad$ High-Income OECD.}

Corruption

Crime \& Theft

Regulation

Taxes

Financing

Inflation

Policy Instability

Poor Infrastructure

1
3
8
5
4
7
6
2

5

6

4

1

2

8

7

3

Source: World Development Report, 1997.

Note that these numbers all come from the end of the period over which we estimated $\hat{g}$ (NGROWTH) and $\bar{\varepsilon}$ (INSTAB). While it would of course be better to have some average measures over the entire period in question, this was the data that we had available and hence what we used. We have reproduced this data in Table 1 below.

Finally, we used this cross sectional data to regress NGROWTH, INFMORT, AGRICULT, LEXPECT, URBAN, PCI and LITERACY on INSTAB (or $\bar{\varepsilon}$ ). In this context, note that albeit the NGROWTH variable was used in defining the value of the INSTAB variable, this was not done in a manner that that would give us any a priori theoretical reason to expect the two variables to be spuriously correlated. On the other hand, the higher the average nominal growth trend the greater the scope for nominal flutuations and instability, hence it is proper to include the NGROWTH variable in our regression equation, even though it is not one of the social attributes that we are concerned with.

Table 3: Regression Results of Select Variables on Economic Instability (INSTAB). 


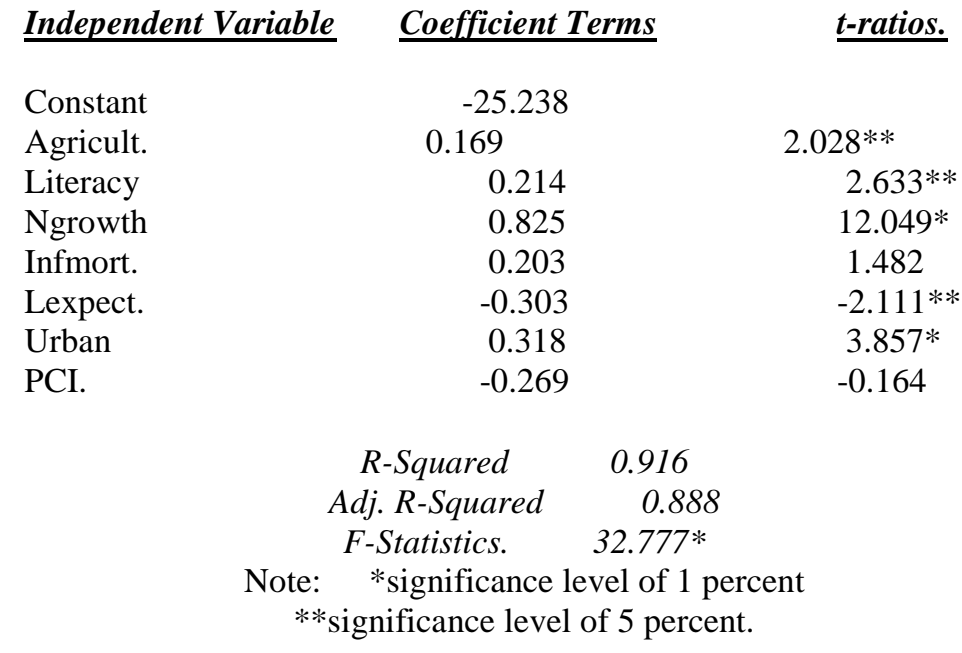

Our regression results are outlined in Table 3 below. The results seem almost too good to be true given our very small sample of only 29 cross-sectional observations. It may seem surprising that Corruption Perception Index has a negative and statistically insignificant coefficient. This result may indicate that corruption may not have such a destabilizing force, because after corruption becomes deeply rooted in a society, it becomes part of the daily routine of business life. As such, its impact becomes quite insignificant as the regression results show. We find litereacy rates to have a positive and statistically significant coefficient. The predicted outcome is that literacy rates will negatively influence economic instability - which also means that it will add positively to the stability of the economy. That conventional rationale does not apply in Africa. Although achieving modernity, and improving literacy rates are essential, but the process breeds instability. Certainly, modernization enhances the ability of a governing group to maintain order, resolve disputes and promote the economic and political welfare of the community. But urbanization, and educational expansion usually involve previously inactive ethnic, religious, and economic groups. As such, the explosion of mass participation in economic/political matters relative to institutions capacity to absorb new participants leads to political and economic instability (see, Hungtington, 1968). Given that most African nations are ethnically and religiously diversed, coupled with the fact that they are mostly in their early stages of economic development, improvement in the literacy rates could impact the stability of the economy negatively. The result from this analysis supports the notion that literacy will positively affect the instability of African economies. All the other variables have the signs we expect. Finally note that we find the adjusted R-square to be $88.8 \%$ which is extraordinarily high for cross-sectional analysis of this kind.

\section{Conclusion}

This paper offers a new nominal definition of economic instability in terms of average standard deviations from the exponential growth path. Given the heterogeneous nature of African economies, this paper will not pretend to have identified all the various factors that have affected the economic stability of these deverse economies. As such, this paper focused on easily measured characteristics like GDP per capita, literacy rates, infant mortality rates, life expectancy rates, corruption index, the percentage of the population engaged in agriculture, and urbanization in explaining the economic instability of African economies.

From the regression results, it becomes imperative that African policy makers most concentrate on policies that will permanently decrease the dual nature of African economies. As already mention, middle income countries have dual economies; a large traditional subsistence agricultural sector in mist of an urban enclaves with modern manufacturing and processing sector The proportion of the labor force working in agriculture, the literacy rates, the percentage of population that reside in the urban sector, and the life expectance are the results of the dual nature of African economies. 
The regression results show that urbanization significantly contributed to the economic instability in African. The urban enclaves continue to attract idle and unproductive labor from rural traditional subsistence agricultural sector. The regression results show that literacy and the percentage of the population engaged in subsistence agriculture both contributed significantly to the economic instability in African. Again, both literacy rates and the percentage of the population engaged in subsistence agriculture have increased over the years mostly as a result of the dual nature of African economies. If economic and educational opportunities are decentralized, parents in rural areas will be able to educate their children and also be able to find gainful employment in the rural sector. That will increase the literacy rates, improve the economic conditions of the rural sector, and may help in reducing the economic instability in Africa.

\section{Recommendations for Further Study}

Given the heterogeneous nature of African economies, especially their history, culture, political system and infrastructure, more empirical research is needed to fully study other sources of economic instability. More empirical study is especially needed to fully investigate why corruption as observed here is not a destabilizing factor. Also, the role of political institution, the existence or lack of democracy in most African nations should be further explored - whether political instability will significantly contribute to economic instability.

\section{End Notes}

1. The rule of law is extremely important for sustainable economic development because the constitution and the system of laws define the parameters of the legal framework within which economic and political activities must take place. According to Professor Ayittey (2001), the rule of law does not exist in many African nations where economic, political leaders and their government ministers flout the law.

2. Corruption drives away foreign investment, and aggravates the budget deficit problem. Political and economic disorder feed on themselves to create institutional breakdown - which may hinder economic development and stability.

3. Investment or development is a creative activity that need enabling environment to exist. This enabling environment includes security of persons and property. In African, most people live in fear of their lives and property. No entrepreneur or businessman will establish a company which would be arbitrarily seized by gun-toting bandit. (see, Ayittey, 2001).

4. This relates to perceptions of the degree of corruption computed from surveys done by Transparency International (TI). Twelve surveys were used and at least three surveys were required for a country to be included in the 1998 corruption perception index.

\section{Reference}

1. Ahmad, Sultan. "Improving Inter-Spatial and Inter-Temporal Comparability of National Accounts." Journal of Development Economics 44: 53-75, 1994.

2. Ayittey, George N. "Business and African Development." Presented during the International Academy of African Business \& Development Conference, 2001. (Unpublished)

3. Central Intelligence Agency. The World Factbook 1993. Washington DC: CIA Office of Public and Agency Information, 1993.

4. $\quad$ Fosu, Augustin Kwasi."Political Instability and Economic Growth." Economic Development and Cultural Change: 829-841, 1992

5. Clunies Ross, Anthony. Economic Stabilization for Developing Countries. Aldershot: Edward Elgar Publishing Co. 1991.

6. "Corruption: A Major Barrier to Sound and Equitable Development," The World Bank Group.. http://www.worldbank.org/html/extdr/backgrd/ibrd/corrupt.htm, 1996.

7. $\quad$ Frankel, Jeffrey and Menzie Chinn. "The Stabilizing Properties of a Nominal GNP Rule." Journal of Money, Credit and Banking 27: 318-334, 1995.

8. Grilli, Enzo. "Long-Term Economic Growth, Income Distribution, and Poverty in Developing Countries: The Evidence." In Enzo Grilli and Dominick Salvatore, eds. Economic Development: Handbook of Com- 
parative Economic Policies, vol. 4: 65-143. Westport, CT: Greenwood Press, 1994.

9. Grootaert, Christiaan. "Structural Change and Poverty in Africa: A Decomposition Analysis for Côte d'Ivoire." Journal of Development Economics 47: 375-401, 1995.

10. Hall, Robert, and N. Gregory Mankiw. "Nominal Income Targeting." In Monetary Policy, edited by N. G. Mankiw. Chicago: University of Chicago Press: 29-52, 1994.

11. Heston, Alan."A Brief Review of Some Problems In Using National Accounts Data In Level of Output Comparisons and Growth Studies." Journal of Development Economics 44: 29-52, 1994.

12. Huntington, Samuel P., Political Order in Changing Societies. New Haven: Yales University Press, 1968.

13. Jonsson, Petur and Amon Okpala. "On Economic Instability in African Economies." Atlantic Economic Journal 25(4): 430, 1997.

14. Little, Ian M., Richard N. Cooper, W. Max Corden and Sarath Rajapatirana. Boom, Crisis, and Adjustment: The Macroeconomic Experience of Developing Countries. New York: Oxford University Press, 1993.

15. Killick, Tony. "Africa's Postindependence Development Experiences." In Enzo Grilli and Dominick Salvatore, eds. Economic Development: Handbook of Comparative Economic Policies, vol. 4: 331-387. Westport, CT: Greenwood Press, 1994.

16. Labini, Paolo Sylos. "The Classical roots of Development Theory." In Enzo Grilli and Dominick Salvatore, eds. Economic Development: Handbook of Comparative Economic Policies, vol. 4: 3-27. Westport, CT: Greenwood Press, 1994.

17. Pomfret, Richard. "North African Regional Development Experience." In Enzo Grilli and Dominick Salvatore, eds. Economic Development: Handbook of Comparative Economic Policies, vol. 4: 553-580. Westport, CT: Greenwood Press, 1994.

18. "Restraining Arbitrary State Action and Corruption," World Development Report, New York: Oxford University Press, 98-109, 1997.

19. Riedel, James. "Strategies of Economic Development." In Enzo Grilli and Dominick Salvatore, eds. Economic Development: Handbook of Comparative Economic Policies, vol. 4: 29-60. Westport, CT: Greenwood Press, 1994.

20. "Securing the Economic and Social Fundamentals," World Development Report, New York: Oxford University Press, 41-60, 1997.

21. "Transparency International: Corruption Perception Index - Data," http://www.gudg.de/ uwvw /CPI1998.html, 1998.

22. World Development Report. New York: Oxford University Press, 1998.

Notes 